\title{
KONTAMINASI DI-ETHYLHEXYL PHTHALATE (DEHP) DARI BOTOL POLIETILENA TEREFTALAT (PET) PADA AIR MINUM SODIS DI YOGYAKARTA TAHUN 2018
}

\author{
Shandytias Widoastuti ${ }^{1}$ ), Sugeng Abdullah ${ }^{2}$ ), Suparmin ${ }^{3}$ ) \\ Jurusan Kesehatan Lingkungan, Politeknik Kesehatan Kemenkes Semarang \\ Jl. Raya Baturraden KM 12 Purwokerto, Indonesia
}

\begin{abstract}
Abstrak
Penggunaan botol plastik PET pada proses Solar Water Desinfection (SODIS) beresiko terjadi migrasi senyawa Di-Ethylhexyl Phthalate (DEHP) ke air minum. DEHP yang bermigrasi ke dalam air minum berbahaya bagi kesehatan manusia karena bersifat karsinogen dan dapat menyebabkan gangguan pada organ reproduksi. Tujuan penelitian ini untuk mengetahui ada tidaknya kontaminasi senyawa kimia Di-Ethylhexyl Phthalate (DEHP) pada air SODIS yang menggunakan botol plastik PET. Jenis penelitian ini adalah pre eksperimental dengan desain the static group comparison design. Dalam penelitian ini terdapat kelompok control dan kelompok perlakuan. Hasil penelitian menunjukkan tidak ada kontaminasi senyawa kimia Di-Ethylhexyl Phthalate (DEHP) pada air SODIS dengan suhu air $37.66^{\circ} \mathrm{C}$. Terdeteksi 10 senyawa kimia yang hilang dan 4 senyawa kimia terdeteksi baru pada air sampel perlakuan SODIS. Salah satu senyawa kimia yang terdeteksi pada air sampel setelah diberi perlakuan SODIS adalah Cyclohexasiloxane, dodecamethyl. Senyawa Cyclohexasiloxane, dodecamethyl tidak memiliki efek serius pada kesehatan manusia. Kesimpulan penelitian adalah tidak terjadi kontaminasi senyawa Di-(2Ethylhexyl Phatalate (DEHP) pada air SODIS yang menggunakan botol plastik PET pada suhu air $37.66^{\circ} \mathrm{C}$. Disarankan untuk masyarakat menggunakan botol kaca sebagai wadah SODIS. Perlu dilakukan penelitian serupa dengan variabel yang bervariasi seperti perbedaan suhu, perbedaan jenis botol, dan lama penjemuran.
\end{abstract}

Kata Kunci ： Di-Ethylhexyl Phthalate (DEHP); Solar Water Desinfection (SODIS); Kesehatan Lingkungan

\begin{abstract}
The use of PET plastic bottles in the Solar Water Desinfection (SODIS) process at risk of migrating Di-Ethylhexyl Phthalate (DEHP) compounds into drinking water. DEHP that migrates into drinking water is harmful to human health because it is carcinogenic and may cause disturbance to the reproductive organs. The purpose of this study was to determine the presence or absence of chemical contamination Di-Ethylhexyl Phthalate (DEHP) in SODIS water using PET plastic bottles.The type of research is pre experimental with the design of static group comparison design. In this study there are control groups and treatment groups.The results showed no contamination of Di-Ethylhexyl Phthalate (DEHP) chemical compounds in SODIS at water temperature $37.66^{\circ} \mathrm{C}$. Detected 10 lost chemical compounds and 4 new detected chemical compounds in SODIS treatment water samples. One of the chemical compounds detected in the sample water after being treated with SODIS is Cyclohexasiloxane, dodecamethyl. Cyclohexasiloxane, dodecamethyl compounds have no serious effects on human health. The conclusion of the study was that there was no contamination of Di 2-Ethylhexyl Phatalate (DEHP) in SODIS water using PET plastic bottle at water temperature $37.66^{\circ}$ C.It was suggested to use glass bottles as SODIS container.It needs to do similar research with variables such as temperature difference, different types of bottles, and duration of sunlight exposure.
\end{abstract}

Keywords $\quad$ : Di-Ethylhexyl Phthalate (DEHP); Solar Water Desinfection (SODIS); Environmental Health

\footnotetext{
1) E-mail: shandytias1996@gmail.com

2) E-mail: sugengzend2016@gmail.com

3) E-mail: pakparmin@yahoo.com
} 


\section{PENDAHULUAN}

Solar Water Desinfection (SODIS) merupakan proses desinfeksi air minum sederhana yang memanfaatkan sinar ultraviolet dan panas matahari untuk membunuh mikroorganisme di dalam air. Cara desinfeksi SODIS ini adalah dengan memasukkan air yang terkontaminasi mikroorganisme ke dalam botol dan dipaparkan sinar matahari penuh selama 5-6 jam apabila cuaca terik, apabila cuaca mendung penjemuran diperpanjang. Dari uji laboratorium dan uji lapangan yang dilakukan Yayasan Dian Desa, SODIS terbukti efektif dalam penurunan kuman dan kematian mikroorganisme dalam air.

Tahun 1997, Yayasan Dian Desa bekerja sama dengan EAWAG/SANDEC dalam pengenalan teknologi SODIS di Indonesia. SODIS telah diperkenalkan di berbagai daerah di Indonesia, terutama di NTT dan NTB. Target pengenalan SODIS diutamakan pada masyarakat yang masih mempunyai kebiasaan minum air mentah (Yayasan Dian Desa, 2016). Teknologi SODIS merupakan alternatif desinfeksi air minum yang murah dan mudah dilakukan di lapangan.

Wadah yang biasa digunakan di masyarakat dalam proses SODIS adalah botol plastik PET. Botol plastik PET memiliki kode 1 di bagian botol. Botol dengan kode 1 ini direkomendasikan hanya sekali pakai. Botol PET tersusun dari polimer yang dapat lepas ke dalam air pada suhu tinggi dan penyimpanan dalam jangka waktu yang lama.

Penggunaan botol plastik PET pada proses SODIS beresiko terjadi migrasi senyawa $\mathrm{Di}$ Ethylhexyl Phthalate (DEHP) ke dalam air minum. DEHP merupakan senyawa kimia organik yang biasa digunakan sebagai bahan pemlastis dalam pembuatan botol plastik. DEHP dapat berimgrasi dari botol plastik ke dalam air dipengaruhi oleh keasaman (pengawet yang digunakan), suhu, dan waktu. Semakin tinggi suhu dan lamanya penyimpanan, maka semakin tinggi pula jumlah DEHP yang bermigrasi. Penyimpanan pada suhu $45^{\circ} \mathrm{C}$ akan meningkatkan difusi DEHP dari dinding botol PET ke dalam produk (Farhoodi, 2008). Menurut Fauzan Amin (2009) nilai pH mempengaruhi kestabilan DEHP, pH asam dapat menyebabkan semakin banyak DEHP yang terlarut sedangkan $\mathrm{pH}$ basa dapat menyebabkan DEHP terdegradasi oleh senyawa lain. oleh suhu, dan lama penyimpanan.

DEHP yang bermigrasi ke dalam air minum berbahaya bagi kesehatan manusia. Berdasarkan International Agency for Research on Cancer (IARC) DEHP termasuk dalam grup karsinogen 2B, yaitu kemungkinan dapat menyebabkan kanker pada manusia. Pada paparan jangka panjang atau kronik DEHP dapat berpengaruh pada hati dan ginjal. Paparan DEHP dosis tinggi juga dapat berdampak pada gangguan organ reproduksi.

Pada proses SODIS botol PET yang berisi air dipaparkan langsung di bawah sinar matahari selama 5-6 jam. Hal ini dapat beresiko terjadinya migrasi DEHP dari botol PET ke dalam air minum.

Tujuan penelitian ini adalah untuk mengetahui ada tidaknya kontaminasi senyawa kimia Di-Ethylhexyl Phthalate (DEHP) pada air SODIS yang menggunakan botol plastik PET.

\section{BAHAN DAN METODE}

Jenis penelitian yang digunakan adalah pre eksperimental dengan desain the static group comparison design Dalam penelitian ini terdapat dua kelompok penelitian yaitu kelompok kontrol dan perlakuan. Kelompok kontrol merupakan air sampel yang tidak dipaparkan sinar matahari selama 6 jam, sedangkan kelompok perlakuan adalah air sampel yang dipaparkan sinar matahari langsung selama 5-6 jam. Sampel dalam penelitian ini diambil dari air sumur pompa warga di Desa Baturetno Kecamatan Banguntapan Kabupaten Bantul, Yogyakarta. Volume air sampel sebanyak $500 \mathrm{ml}$. Jenis botol yang digunakan adalah botol plastik PET. Pemeriksaan DEHP dilakukan dengan menggunakan GC-MS Thermoscientific seri TG5MS di Laboratorium Penelitian dan Pengujian Terpadu (LPPT) Universitas Gadjah Mada Yogyakarta.

\section{HASIL DAN PEMBAHASAN}

\section{Kualitas Fisik Air Sampel SODIS}

Kualitas fisik air sampel tidak keruh, tidak berwarna, dan tidak berbau. Kekeruhan dalam air dapat mengganggu keefektifan SODIS dalam mendesinfeksi air. Partikel-partikel kekeruhan dalam air menyebabkan mikroorganisme terlindungi dari radiasi sinar matahari sehingga mikroorganisme tidak mati (Yoga Setiawan, 2010). Oleh karena itu, air yang akan dilakukan SODIS semaksimal mungkin kekeruhannya di bawah 30 NTU.

\section{Kondisi Cuaca}

Kondisi cuaca saat perlakuan SODIS dilakukan adalah cerah berawan. Suhu udara antara $29^{\circ} \mathrm{C}-38^{\circ} \mathrm{C}$ kecepatan angin $0,66 \mathrm{~m} / \mathrm{s}$, indeks UV 6. SODIS dapat diterapkan secara efektif bila intensitas sinar matahari tersedia paling sedikit $500 \mathrm{~W} / \mathrm{m}^{2}$. Indeks UV merupakan simplifikasi dari pengukuran radiasi sinar matahari (Sugeng Abdullah, 2017). Indeks UV pada tempat perlakuan SODIS adalah 6. Pada 
indeks UV 6 berarti pancaran sinar matahari tinggi. Indeks UV pada tempat dilakukan percobaan cocok untuk proses SODIS.

\section{Pengukuran Suhu Udara Lingkungan Air Sampel Kontrol dan Perlakuan SODIS}

Tabel. 1 Hasil Pengukuran Suhu Udara

\begin{tabular}{ccc}
\hline $\begin{array}{c}\text { Suhu Udara } \\
\text { Jam Ke- }\end{array}$ & \multicolumn{2}{c}{ Kode Saampel } \\
\cline { 2 - 3 } & $\begin{array}{c}\text { Kontrol } \\
\left({ }^{\circ} \mathrm{C}\right)\end{array}$ & $\begin{array}{c}\text { Perlakuan } \\
\left({ }^{\circ} \mathrm{C}\right)\end{array}$ \\
\hline 1 & 32,2 & 33,2 \\
2 & 29,9 & 35,8 \\
3 & 29,9 & 35,6 \\
4 & 30 & 32,5 \\
5 & 31,3 & 35,3 \\
6 & 30,9 & 32,1 \\
\hline Rerata & 30,7 & 34,0 \\
\hline
\end{tabular}

Sumber : Data Primer, 2018

Perbedaan suhu udara pada kedua sampel dapat dipengaruhi oleh lamanya penyinaran matahari. Pada penelitian ini sampel kontrol diletakkan di dalam rumah yang tidak terpapar sinar matahari. Sedangkan sampel perlakuan diletakkan di luar rumah yang langsung tepapar sinar matahari selama 6 jam. Oleh karena itu, suhu udara pada sampel perlakuan lebih tinggi dibandingkan dengan suhu udara sampel kontrol. Suhu udara akan mempengaruhi suhu materi yang ada disekitarnya termasuk suhu air dalam botol SODIS. Apabila suhu air tinggi maka proses pembunuhan mikroorganisme dalam air akan lebih efektif. Oleh karena itu suhu udara berpengaruh pada proses SODIS.

\section{Pengukuran Suhu Air pada Sampel Kontrol dan Perlakuan SODIS}

Tabel. 2 Hasil Pengukuran Suhu Air

\begin{tabular}{ccc}
\hline \multirow{2}{*}{$\begin{array}{c}\text { Suhu Air } \\
\text { Jam Ke- }\end{array}$} & \multicolumn{2}{c}{ Kode Saampel } \\
\cline { 2 - 3 } & $\begin{array}{c}\text { Kontrol } \\
\left({ }^{\circ} \mathrm{C}\right)\end{array}$ & $\begin{array}{c}\text { Perlakuan } \\
\left({ }^{\circ} \mathrm{C}\right)\end{array}$ \\
\hline 1 & 27 & 25 \\
2 & 28 & 40,5 \\
3 & 28 & 41,5 \\
4 & 28 & 38 \\
5 & 28 & 36 \\
6 & 28 & 35 \\
\hline Rerata & 27,83 & 37,66 \\
\hline
\end{tabular}

Sumber : Data Primer, 2018

Berdasarkan tabel 2 Suhu air pada sampel kontrol lebih rendah dibandingkan dengan suhu air pada sampel perlakuan. Perbedaan suhu air disebabkan peletakkan sampel. Sampel kontrol berada pada suhu lingkungan $30,7^{\circ} \mathrm{C}$ yang tidak terpapar sinar matahari tidak mengalami peningkatan suhu air yang tinggi dibandingkan dengan sampel perlakuan. Sampel perlakuan berada pada suhu lingkungan $34,08^{\circ} \mathrm{C}$ yang terpapar langsung dengan sinar matahari mengalami peningkatan suhu air yang tinggi. Suhu air dalam botol dapat mempengaruhi proses migrasi bahan-bahan yang terdapat dalam kemasan botol plastik khususnya DEHP ke dalam air. Semakin tinggi suhu, maka semakin tinggi DEHP yang bermigrasi. Menurut Farhoodi (2008) pada suhu $45^{\circ} \mathrm{C}$ dapat meningkatkan migrasi DEHP dari dinding botol PET ke dalam air. Hasil pengukuran suhu pada air sampel SODIS tidak mencapai suhu $45^{\circ} \mathrm{C}$, sehingga DEHP tidak bermigrasi ke dalam air SODIS atau kandungan DEHP pada air sampel di bawah limit deteksi alat.

\section{Pengukuran pH pada Air Sampel Kontrol dan Perlakuan SODIS}

Tabel. 3. Hasil Pengukuran pH

\begin{tabular}{lll}
\hline KODE & \multicolumn{2}{c}{$\mathrm{pH}$} \\
\cline { 2 - 3 } SAMPEL & Sebelum & Sesudah \\
\hline Kontrol & 8 & 8 \\
Perlakuan & 8 & 8 \\
\hline Sur
\end{tabular}

Sumber : Data Primer, 2018

Berdasarkan tabel 3 nilai $\mathrm{pH}$ sebelum dan sesudah perlakuan SODIS basa. Tidak bermigrasinya DEHP pada air sampel yang diperiksa dapat dipengaruhi oleh pH basa. Menurut Fauzan Amin (2009) nilai pH mempengaruhi kestabilan DEHP, $\mathrm{pH}$ asam dapat menyebabkan semakin banyak DEHP yang terlarut sedangkan $\mathrm{pH}$ basa dapat menyebabkan DEHP terdegradasi oleh senyawa lain.

\section{Pengukuran Kecepatan Angin di Lingkungan Kontrol dan Perlakuan SODIS}

Tabel 4. Hasil Pengukuran Kecepatan Angin

\begin{tabular}{ccc}
\hline \multirow{2}{*}{$\begin{array}{c}\text { Kecepatan Angin } \\
\text { Pengukuran Ke- }\end{array}$} & \multicolumn{2}{c}{ Kode Saampel } \\
\cline { 2 - 3 }$(\mathrm{m} / \mathrm{s})$ & $\begin{array}{c}\text { Kontrol } \\
(\mathrm{m} / \mathrm{s})\end{array}$ \\
\hline 1 & 0 & 1,1 \\
2 & 0,1 & 1,3 \\
3 & 0,3 & 1,6 \\
4 & 0 & 1,2 \\
5 & 0,1 & 1,1 \\
6 & 0,3 & 1,6 \\
7 & 0,1 & 1,2 \\
8 & 0 & 1,2 \\
9 & 0,3 & 1,2 \\
10 & 0,1 & 0,7 \\
\hline Rerata & 0,13 & 1,23 \\
\hline
\end{tabular}

Sumber : Data Primer, 2018

Berdasarkan tabel 4 rerata kecepatan angin dalam rumah $0.13 \mathrm{~m} / \mathrm{s}$ sedangkan kecepatan angin di lingkungan perlakuan SODIS $1.23 \mathrm{~m} / \mathrm{s}$. Uji lapangan yang dilakukan Yayasan Dian Desa Yogyakarta (2002), tiupan angin kuat $(11.11 \mathrm{~m} / \mathrm{s}$ - 
$13.9 \mathrm{~m} / \mathrm{s}$ ) dapat mempengaruhi suhu air dalam botol. Pada kondisi suhu udara panas dan tiupan angin kuat, maka suhu dapat turun karena terjadi pelepasan kalor di lingkungan tersebut. Menurut skala Beaufort kecepatan angin $<2.5 \mathrm{~m} / \mathrm{s}$ termasuk dalam kategori kecepatan angin lemah. Berdasarkan hal tersebut, maka kecepatan angin saat proses SODIS tidak berpengaruh pada suhu air dalam botol.

\section{Pemeriksaan DEHP Pada Sampel Kontrol dan Perlakuan SODIS}

Tabel 5.Hasil Pemeriksaan DEHP dengan GC-MS

\begin{tabular}{lll}
\hline Kode & Hasil & Keterangan \\
Sampel & DEHP & \\
\hline Kontrol & Tidak & Terdeteksi \\
& Terdeteksi & senyawa kimia lain \\
Perlakuan & Tidak & Terdeteksi \\
& Tedeteksi & senyawa kimia lain \\
\hline
\end{tabular}

Sumber : Data Primer, 2018

Berdasarkan tabel 5 tidak terdeteksi senyawa Di-(2-Ethylhexyl) Phatalate (DEHP) pada air sampel kontrol dan perlakuan. Pada kedua air sampel terdeteksi senyawa kimia lain. Senyawa kimia lain yang terdeteksi pada air sampel control dan perlakuan dapat dilihat pada tabel 6 dan tabel 7.

Tabel 6. Senyawa Kimia Lain yang Terdeteksi Pada Air Sampel Control

\begin{tabular}{|c|c|c|}
\hline No & Nama Senyawa Kimia & Keterangan \\
\hline$(1)$ & (2) & (3) \\
\hline 1. & Hexadecanoic Acid, methyl ester & Bahan anti mikroba \\
\hline 2. & Hexadecanoic acid, 14-methyl-, methyl ester & Bahan pensanitasi \\
\hline 3. & Pentadecanoic acid, 13-methyl-, methyl ester & Bahan pensanitasi \\
\hline 4. & 9-Octadecanoic Acid & Bahan anti embun \\
\hline 5. & $\begin{array}{l}(5 \beta) \text { Pregnane-3,20ß-diol, } \quad 14 a, 18 a-[4--m e t h y l-3-o x o-(1-o x a-4- \\
\text { azabutane-1,4-diyl)]-, diacetate. }\end{array}$ & \\
\hline 6. & Hexasiloxane, 1,1,3,3,5,5,7,7,9,9,11,11-dodecamethyl & \\
\hline 7. & $1,1,3,3,5,5,7,7,9,9,11,11,13,13,15,15-$ & \\
\hline 8. & 2,6-Dihydroxyacetophenone, 2 TMS derivative & Bahan penyedap \\
\hline 9. & Phosphonoacetic Acid & Bahan anti mikroba \\
\hline 10. & $\begin{array}{l}\text { 2,4-Imidazolidinedione, 5-[3,4-bis[(trimethylsilyl)oxy]phenyl]-3- } \\
\text { methyl-5-phenyl-1-(trimethylsilyl) }\end{array}$ & Bahan pemodifikasi plastik \\
\hline 11. & $\begin{array}{l}\text { Silane, } \quad[[(3 \beta, 11 \beta, 20 S) \text {-pregn-5-ene-3,11,17,20 } \\
\text { tetrayl]tetrakis(oxy)]tetrakis[trimethyl. }\end{array}$ & \\
\hline 12. & Ethyl iso-allocholate & Anti mikroba \\
\hline 13. & $\begin{array}{l}\text { Cyclopropanebutanoic } \quad \text { acid, } \\
\text { pentylcyclopropyl)methyl]cyclopropyl]methyl]cyclopropyl]methyl } \\
\text { ]-, methyl ester }\end{array}$ & \\
\hline 14. & Oxiraneundecanoic acid, 3-pentyl-, methyl ester, trans & Bahan penstabil/antioksidan \\
\hline 15. & 2,5 Dihydroxybenzoic acid, $3 T M S$ derivate & Bahan untuk sintesis \\
\hline 16. & Heptasiloxane, 1,1,3,3,5,5,7,7,9,9,11,11,13,13-tetradecamethyl. & \\
\hline 17. & $\begin{array}{l}\text { 4aa,4b } \beta \text {-Gibbane-1a,10ß-dicarboxylic acid, } \\
\text { hydroxy-1-methyl-8-methylene-, dimethyl ester. }\end{array}$ & Bahan pemodifikasi plastik \\
\hline 18. & Methyl glycocholate, 3TMS derivative & \\
\hline 19. & $\begin{array}{l}\text { 2,4,6(1H,3H,5H)-Pyrimidinetrione, } \\
\text { bis[(trimethylsilyl)oxy]-2-propenyl]-1,3-dimethyl-5-(1- } \\
\text { methylbutyl) }\end{array}$ & Bahan pewarna plastik \\
\hline
\end{tabular}


20. $\quad \beta$-D-Galactopyranoside, methyl 2,3-bis-O-(trimethylsilyl)-, cyclic

Bahan penstabil butylboronate

21. 3-Pyridinecarboxylic acid, 2,7,10-tris(acetyloxy)1,1a,2,3,4,6,7,10,11,11a-decahydro-

22. Heptasiloxane, 1,1,3,3,5,5,7,7,9,9,11,11,13,13-tetradecamethyl

23. (22S)-21-Acetoxy-6a,17a-propylmethylenedioxypregna-1,4- Inflammatory diene-3,20-dione

24. 2-[4-methyl-6-(2,6,6-trimethylcyclohex-1-enyl)hexa-1,3,5trienyl]cyclohex-1-en-1-carboxaldehyde

25. psi.,.psi.-Carotene, 1,1',2,2'-tetrahydro-1,1'-dimethoxy

Nutrient

26. Panstroside

Berdasarkan tabel 6 terdeteksi 26 senyawa kimia lain pada air sampel kontrol yang diperiksa menggunakan GC-MS.

Tabel 7. Senyawa Kimia Lain yang Terdeteksi Pada Air Sampel Perlakuan SODIS

\begin{tabular}{|c|c|c|}
\hline No & Nama Senyawa Kimia & Keterangan \\
\hline$(1)$ & (2) & (3) \\
\hline 1. & Hexadecanoic Acid, methyl ester & Bahan anti mikroba \\
\hline 2. & Hexadecanoic acid, 14-methyl-, methyl ester & Bahan pensanitasi \\
\hline 3. & 13-methyl-, methyl ester & Bahan pensanitasi \\
\hline 4. & 9-Octadecanoic Acid & Bahan anti embun \\
\hline 5. & $\begin{array}{l}\text { (5ß)Pregnane-3,20 } 3 \text {-diol, } 14 a, 18 a-[4--m e t h y l-3 \text {-oxo-(1-oxa-4- } \\
\text { azabutane-1,4-diyl)]-, diacetate. }\end{array}$ & \\
\hline 6. & Hexasiloxane, 1,1,3,3,5,5,7,7,9,9,11,11-dodecamethyl & \\
\hline 7. & $\begin{array}{l}\text { Octasiloxane } \\
\text { hexadecamethyl; }\end{array} \quad 1,1,3,3,5,5,7,7,9,9,11,11,13,13,15,15-$ & \\
\hline 8. & Phosphonoacetic Acid & Bahan antimikroba \\
\hline 9. & $\begin{array}{l}\text { 2,4-Imidazolidinedione, 5-[3,4-bis[(trimethylsilyl)oxy]phenyl]-3- } \\
\text { methyl-5-phenyl-1-(trimethylsilyl) }\end{array}$ & Bahan pemodifikasi plastik \\
\hline 10. & Ethyl iso-allocholate & Anti mikroba \\
\hline 11. & $\begin{array}{l}\text { 2-[[2-[[2-[(2- } \\
\text { pentylcyclopropyl)methyl]cyclopropyl]methyl]cyclopropyl]methyl } \\
]-, \text { methyl ester }\end{array}$ & \\
\hline 12. & Oxiraneundecanoic acid, 3-pentyl-, methyl ester, trans & Bahan penstabil/antioksidan \\
\hline 13. & 2,5 Dihydroxybenzoic acid, 3TMS derivate & Bahan kimia untuk sintesis \\
\hline 14. & Heptasiloxane, 1,1,3,3,5,5,7,7,9,9,11,11,13,13-tetradecamethyl. & \\
\hline 15 . & Methyl glycocholate, 3TMS derivative & \\
\hline 16. & $\begin{array}{l}\text { 2,4,6(1H,3H,5H)-Pyrimidinetrione, } 5-[2,3- \\
\text { bis[(trimethylsilyl)oxy]-2-propenyl]-1,3-dimethyl-5-(1- } \\
\text { methylbutyl) }\end{array}$ & Bahan pewarna plastik \\
\hline & 3-Pyridinecarboxylic acid, 2,7,10-tris(acetyloxy)- & \\
\hline 17. & 1,1a,2,3,4,6,7,10,11,11a-decahydro- & \\
\hline 18. & Heptasiloxane, 1,1,3,3,5,5,7,7,9,9,11,11,13,13-tetradecamethyl & \\
\hline 19. & Cyclohexasiloxane, dodecamethyl & Zat silicon organik \\
\hline 20 & Cycloheptasiloxane, tetradecamethyl & \\
\hline 21. & Nor-diazepam, 3-[[N-hydroxymethyl]aminocarbonyloxy] & \\
\hline 22. & Docosanoic acid, 1,2,3-propanetriyl ester & \\
\hline
\end{tabular}

Berdasarkan tabel 7 terdeteksi 22 senyawa kimia lain pada air sampel setelah diberi perlakuan SODIS. 


\section{Analisis Terjadinya Kontaminasi DEHP Pada Air SODIS}

DEHP dapat bermigrasi kedalam air karena kemampuannya membentuk sistem koloid dengan air (European Chemicals dalam Fauzan Amin, 2008). Menurut Bosnir et al dalam Fauzan Amin (2009) migrasi DEHP dipengaruhi oleh keasaman (pengawet yang digunakan), suhu dan waktu penyimpanan. Semakin tinggi suhu dan lama penyimpanan maka semakin tinggi DEHP yang bermigrasi. Menurut Farhoodi (2008) pada suhu $45^{\circ} \mathrm{C}$ dapat meningkatkan migrasi DEHP dari dinding botol PET ke dalam air. Berdasarkan penelitian Van der Heide dalam F.G Winarno (1994) migrasi dapat terjadi pada suhu $25^{\circ} \mathrm{C}$ dengan penyimpanan selama 6 bulan. Nilai $\mathrm{pH}$ mempengaruhi migrasi DEHP, $\mathrm{pH}$ asam dapat menyebabkan semakin banyak DEHP yang terlarut sedangkan $\mathrm{pH}$ basa dapat menyebabkan DEHP terdegradasi oleh senyawa lain (Fauzan Amin. 2009). Keberadaan DEHP pada air minum dapat mengganggu kesehatan manusia. Berdasarkan International Agency for Research on Cancer (IARC) DEHP termasuk dalam grup karsinogen 2B, yaitu kemungkinan dapat menyebabkan kanker pada manusia. Pada paparan jangka panjang atau kronik DEHP dapat berpengaruh pada hati dan ginjal. DEHP juga dapat menyebabkan gangguan pada organ reproduksi. Penggunaan DEHP sebagai bahan pemlastis pada botol plastik telah diatur dalam Peraturan Kepala Badan Pengawas Obat Dan Makanan Republik Indonesia Nomor Hk.03.1.23.07.11.6664 Tahun 2011 Tentang Pengawasan Kemasan Pangan. Batas migrasi untuk bahan pemlastis Di-(2-Ethylhexyl) Phatalate (DEHP) yaitu 1,5 bpj.

Menurut BPOM meminum air dalam botol plastik yang terpapar sinar matahari tidak berbahaya. Setiap kemasan plastik berpotensi melepaskan komponen penyusunnya ke dalam produk. Pelepasan komponen tersebut dapat terjadi pada suhu tinggi dan kontak yang lama. Meski begitu proses produksi yang dilakukan oleh industri kemasan plastik sudah sesuai dengan prosedur, sehingga komponen penyusun yang terlepas sesuai dengan persyaratan dan tidak menimbulkan resiko bagi kesehatan. BPOM RI telah melakukan pengawasan dan kajian terhadap beberapa jenis kemasan plastik, hasilnya menunjukkan bahwa tingkat paparan masyarakat Indonesia masih dalam taraf aman (Kumparan, 19 Maret 2018).

Berdasarkan hal tersebut, maka penggunaan botol plastik aman digunakan untuk proses SODIS. Meskipun demikian perlu diwaspadai apabila suhu air dalam botol PET mencapai suhu $\geq 45^{\circ} \mathrm{C}$ yang dapat terjadi pada paparan terik matahari dalam waktu cukup lama (5-6 jam). Pada suhu air mencapai $\geq 45^{\circ} \mathrm{C}$ senyawa DEHP dapat bermigrasi ke dalam air minum. Penggunaan botol PET yang berulang-ulang juga dapat meningkatkan migrasi DEHP ke dalam air minum. Untuk itu penggunaan botol kaca lebih aman digunakan sebagai wadah SODIS karena botol kaca tahan terhadap panas dan tidak mudah bereaksi secara kimia.

\section{Identifikasi Senyawa Kimia Lain yang Terdeteksi Pada Air Sampel Kontrol dan Perlakuan SODIS}

Senyawa kimia lain yang terdeteksi pada sampel kontrol sebanyak 26, sedangkan pada sampel perlakuan terdeteksi 22 senyawa kimia lain. Beberapa senyawa kimia lain yang terdeteksi pada kedua sampel digunakan sebagai bahan pembuatan kemasan plastik seperti bahan anti mikroba, bahan pewarna plastik, bahan anti embun, bahan perekat plastik, dll. Terdeteksi senyawa Hexadecanoic Acid, methyl ester pada kedua sampel. Kegunaan senyawa tersebut adalah sebagai bahan anti mikroba dalam pembuatan kemasan plastik berdasarkan safety data sheet (www.merckmillipore.com) senyawa ini tidak termasuk dalam senyawa kimia berbahaya. Senyawa kimia lain yang ditemukan pada kedua sampel adalah 2,5-Dihydroxybenzoic acid. Senyawa 2,5-Dihydroxybenzoic acid merupakan senyawa kimia untuk sintesis. Berdasarkan Lembaran Data Keselamatan Bahan menurut Peraturan (UE) No. 1907/2006 senyawa ini tidak diklasifikasikan sebagai senyawa kimia berbahaya.

Pada sampel perlakuan terdeteksi 10 senyawa kimia hilang dan 4 senyawa kimia yang terdeteksi baru. Senyawa kimia yang terdeteksi baru pada sampel perlakuan dapat dipengaruhi oleh proses penjemuran di bawah sinar matahari selama 6 jam. Senyawa kimia baru tersebut salah satunya adalah Cyclohexasiloxane, dodecamethyl. Menurut Environment Canada (2008) Cyclohexasiloxane, dodecamethyl adalah zat silikon organik yang digunakan dalam produksi polimer silikon. Tidak ada data karsinogenisitas pada senyawa Cyclohexasiloxane, dodecamethyl. Senyawa ini tidak memiliki efek serius pada kesehatan manusia. Dari pembahasan di atas senyawa kimia lain yang teredeteksi pada sampel diketahui keberadaannya tidak membahayakan bagi kesehatan manusia.

\section{SIMPULAN DAN SARAN}

\section{SIMPULAN}

Tidak terjadi kontaminasi senyawa Di-(2Ethylhexyl Phatalate) (DEHP) pada air dalam botol PET yang tidak dijemur di bawah sinar matahari (kontrol) pada suhu air $27.83^{\circ} \mathrm{C}$. Tidak terjadi kontaminasi senyawa Di-(2-Ethylhexyl Phatalate) 
(DEHP) pada air dalam botol PET yang dijemur di bawah sinar matahari (perlakuan SODIS) pada suhu air $37.66^{\circ} \mathrm{C}$. Terdeteksi 10 senyawa kimia yang hilang dan 4 senyawa kimia baru pada air dalam botol PET yang dijemur di bawah sinar matahari (perlakuan SODIS). Salah satu senyawa kimia baru yang terdeteksi adalah senyawa Cyclohexasiloxane, dodecamethyl. Senyawa Cyclohexasiloxane, dodecamethyl tidak memiliki efek serius pada kesehatan manusia.

\section{SARAN}

Peneliti menyarankan kepada masyarakat untuk menggunakan botol kaca sebagai wadah SODIS. Karena botol kaca tahan terhadap panas dan tidak mudah bereaksi secara kimia. Pada proses SODIS suhu air tidak dapat dikontrol. Pada suhu air di bawah $45^{\circ} \mathrm{C}$ terdeteksi senyawa kimia lain, sedangkan pada suhu air $\geq 45^{\circ} \mathrm{C}$ beresiko terjadi migrasi DEHP ke dalam air minum. Bagi peneliti selanjutnya : perlu dilakukan penelitian serupa dengan variabel yang bervariasi seperti perbedaan suhu, perbedaan jenis botol, dan lama penjemuran. Perlu dilakukannya penelitian atau pencarian informasi terhadap kegunaan senyawa kimia lain yang terdeteksi dan dampaknya terhadap kesehatan manusia.

\section{DAFTAR PUSTAKA}

Radiasi Matahari, Radiasi Bumi dan Neraca Radiasi Sistem Bumi-Atmosfer . (2017, Desember 30). Retrieved Maret 30, 2018, from

www.geomacorner.com/2017/12/radiasimatahari-radiasi-bumi-dan-neraca-radiasisistem-bumi-atmosfer.htm

Amin, F. (2009). Evaluasi Migrasi Migrasi Di-(2Ethylhexyl) Ftalat Dari Botol Polietilena Tereftalat Menggunakan GC-MS. Bogor: Fakultas Matematika dan Ilmu Pengetahuan Alam Institut Pertanian Bogor.

Christina Aristanti, d. (2005). Manual Teknis dan Desiminasi SODIS. Retrieved Januari 16, 2018, from https://issuu.com/yonotimore/docs/manual sodis.

Dasar. Retrieved Januari 3, 2018, from http://www.depkes.go.id/development/site/ $\mathrm{jkn} /$ index.php?cid=875\&id=kekuranganak ses-terhadap-air-minum-dan-sanitasidasar.html.
Kepala Badan Pengawas Obat dan Makanan Republik Indonesia. (Tahun 2011). Peraturan Kepala Badan Pengawas Obat dan Makanan Republik Indonesia Nomor HK.03.1.23.07.11.6664 Tentang Pengawasan Kemasan Pangan.

Kepala Badan Pengawas Obat Dan Makanan Republik Indonesia. (Tahun 2011). Peraturan Kepala Badan Pengawas Obat Dan Makanan Republik Indonesia Nomor HK.03.1.23.07.11.6664 Tentang Pengawasan Kemasan Pangan.

Kumparan. (2018, Maret 19). BPOM : Tidak Benar Air Kemasan yang Ditinggal di Dalam Mobil Berbahaya. kumparanNEWS.

Mariska, B. (2011). Gas Chromatography Mass Spectrometry (GC-MS). Retrieved Desember 30, 2017, from http://bonimariska.blogspot.co.id/2011/05/ font-definitions-font-face font.html

Menteri Kesehatan RI. (2010). Peraturan Menteri Kesehatan Nomor 492 Tahun 2010 Tentang Persyaratan Kualitas Air Minum. Jakarta: Kementerian Kesehatan Republik Indonesia.

Misbahudin, E. (2007). Pengaruh Alat SODIS Botol Kaca Terhadap Penurunan Kandungan Coliform Air Sumur Gali Di Desa Pamijen RWI RT 5 Kecamatan Baturraden Tahun 2007. Purwokerto: Kementrian Kesehatan Semarang Jurusan Kesehatan Lingkungan Purwokerto.

Nusa Idman Said. (2008). Teknologi Pengolahan Air. Pusat Teknologi Lingkungan, Deputi Bidang Teknologi Pengembangan Sumber Daya Alam Badan Pengkajian dan Penerapan Teknologi (BPPT).

Okik Hendriyanto C. (n.d.). Pengaruh Intensitas Sinar Ultraviolet dan Pengadukan Terhadap Reduksi Jumlah Bakteri E.Coli . Jawa Timur: Progdi Teknik Lingkungan, Fakultas Teknik Sipil dan Perencanaan. Universitas Pembangunan Nasional (Veteran).

Oxyana Saravirgizma. (2010). Validasi Metode Analisis Ftalat Sebagai Migran Dari Kemasan Pada Simulan Pangan. Bogor : Fakultas Teknologi Pertanian Institut Pertanian Bogor. 
Pemerintah Kabupaten Bantul Kecamatan Banguntapan. (n.d.). Profil Kabupaten Bantul. Retrieved from https://kecbanguntapan.bantulkab.go.id/hal/profi

Pratiwi Retno. (2010). Pengembangan Metode Penentuan Kadar DEHP dan Analisis Migrasi DEHP ke dalam Simulan Pangan di Pusat Riset Obat dan Makanan, Badan POM RI. Bogor: Fakultas Teknologi Pertanian Institut Pertanian Bogor.

Pubchem. (2004). Open Chemistry Database. Retrieved from https://pubchem.ncbi.nlm.nih.gov/compou $\underline{\text { nd/Phosphonoacetic acid\#section=Top }}$

Rahmawati, N. F. (2016). Kualitas Mikrobiologi Air Sumur Berdasarkan Total Coliform di Kabupaten Trenggalek Prosiding Seminar Nasional II Tahun 2016. Malang: Pendidikan Matematika dan Ilmu Pengetahuan Alam Program Studi Pendidikan Biologi Fakultas Keguruan dan Ilmu Pendidikan Universitas Muhammadiyah Malang.

RI, K. K. (n.d.). Kekurangan Akses Tehadap Air Minum dan Sanitasi Dasar. Retrieved Januari 3, 2018, from http://www.depkes.go.id/development/site/ jkn/index.php?cid=875\&id=kekuranganak ses-terhadap-air-minum-dan-sanitasidasar.html.

Samadi. (2007). In Samadi, Geografi 1 SMA Kelas $x$ (pp. 117-118). Yudhistira.

Schmid Peter. dkk. (2008). Does The Reuse Of PET Bottles During Solar Water Disinfection Pose A Health Risk Due To The Migration Of Plasticisers And Other Chemicals Into The Water. Water Research. Retrieved from

https://www.ncbi.nlm.nih.gov/pubmed/18 $\underline{929387}$

Subdit Pengendalian Diare dan Infeksi Saluran Pencernaan Kemenkes RI. (2011). Pengendalian Diare di Indonesia. www.depkes.go.id/download.php?file=do wnload/pusdatin/...diare... .

Sugeng Abdullah. (2017, September 29). UV-Index Estimator. Retrieved April 4, 2018, from Kesehatan Lingkungan: http://sugengzend.blogspot.co.id/2017/09/ uv-index-estimator.html
Sumarno, E. (n.d.). Radiasi Matahari. Retrieved Desember 30, 2017, from http://www.academia.edu/8728067/RADI ASI_MATAHARI

Suparmin. (2002). Kimia Untuk Analisis Air dan Air Limbah. Purwokerto: Politeknik Kesehatan Semarang Jurusan Kesehatan Lingkungan Purwokerto.

Susianto, N. (n.d.). Artikel Kadar Hidrokarbon. Retrieved Januari 15, 2018, from http://www.studiobelajar.com/kadar hidrokarbon/

Swarjana, I. K. (2015). Metodologi Penelitian Kesehatan(Edisi Revisi). Yogyakarta: ANDI.

Titah Nurul Romadhani. (2006). Studi Komparasi Penurunan Kandungan Coliform Sesudah Kontak Dengan Sinar Matahari 4 dan 5 jam Pada SODIS Di RT 02 RW 06 Desa Klahang Kecamatan Sokaraja Kabupaten Banyumas Tahun 2006. Purwokerto: Kementerian Kesehatan RI Politeknik Kesehatan Semarang Jurusan Kesehatan Lingkungan.

Tri Cahyono. (2018). Pedoman Penulisan Proposal Penelitian dan Karyatulis . Purwokerto : Politeknik Kesehatan Kementrian Kesehatan Semarang Jurusan Kesehatan Lingkungan Purwokerto.

Triyanto. (2012). Perencanaan Eksperimen . Retrieved Desember 14, 2017, from https://triyantounsoed.wordpress.com/201 2/01/15/perencanaaneksperimen

Winarso., F. (1994). Bahan Tambahan Untuk Makanan dan Kontaminan. Bogor: Pustaka Sinar Harapan.

Wita Widya Pratiwi. (2011). Studi Komparasi Kandungan Bakteri Coliform Antara Air Minum SODIS Yang Dibuat Dengan Media Botol Plastik Dan Media Botol Kaca Tahun 2011. Purwokerto: Kementerian Kesehatan RI Politeknik Kesehatan Semarang Jurusan Kesehatan Lingkungan Purwokerto.

Yoga Setiawan. (2010). SODIS (SOLAR WATER DISINFECTION) : Metode Praktis Mendapatkan Air Layak Minum Yang Bebas Bakteri . Dalam Lomba Penulisan Artikel Ilmiah Pertanian Berbasis Web TPB IPB 2010. 